\title{
Ultrasound measurement of fetal abdominal subcutaneous tissue thickness as a predictor of large versus small fetuses for gestational age
}

\author{
Esraa A. Khalifa*, Shaimaa A. Hassanein and Hazem H. Eid
}

\begin{abstract}
Background: Commonly used ultrasound fetal weight estimation formulas show variable degrees of error which is more evident in fetuses with nutritional and metabolic issues; better accuracy of fetal weight estimation can be obtained by incorporation of fetal soft tissue parameters like the fetal subcutaneous tissue in the weight estimation process. The aim of this study was to assess the accuracy of fetal abdominal subcutaneous tissue thickness (FASTT) as an indicator of fetal birth weight.

Results: FASTT showed a high significant statistical correlation with fetal birth weight $(r=0.94, P$ value $=0.00)$; it showed higher sensitivity for large for gestational age (LGA) than small for gestational age (SGA) $(90.9 \%$ and $86.9 \%$, respectively). The best cutoff value for the detection of LGA was $\geq 9.2 \mathrm{~mm}$ and $\leq 4.5$ for SGA. FASTT showed lower accuracy than abdominal circumference (AC) as an indicator of LGA (92\% versus $96 \%$, respectively). Used alone, FASTT is less sensitive than Hadlock formula in both LGA and SGA (90.9\% versus $94.5 \%$ in LGA and $86.9 \%$ versus 88.9\% for SGA, respectively). There was no statistical correlation between FASTT and mode of delivery $(r=0.09, P$ value $=0.23)$ nor fetal gender $(r=0.15, P$ value $=0.11)$

Conclusion: FASTT is a good indicator of fetal birth weight especially LGA, yet it is less sensitive than AC in the prediction of LGA. It cannot be used as a predictor of mode of delivery and not affected by fetal gender.
\end{abstract}

Keywords: Birth weight, Large for gestational age, Small for gestational age, Subcutaneous tissue

\section{Background}

Fetal growth is a process of complex interactions between several maternal, fetal, and placental factor [1]. Proper fetal weight assessment leads to better management of high-risk pregnancies as fetal weight is an important determinant of neonatal survival [2].

Ultrasound is the best used technique for fetal growth monitoring and fetal weight estimation. However, all the commonly used weight estimation formulas show a variable degree of error, so improving the traditional methods of ultrasonographic fetal weight estimation methods is required for better degree of precision [3].

\footnotetext{
* Correspondence: Esraa.khalifa@med.menofia.edu.eg

Department of Radiodiagnosis, Faculty of Medicine, Menoufia University, Shibin El Kom, Menoufia 32511, Egypt
}

The use of MRI (magnetic resonance imaging) in fetal weight estimation is under study. Although not widely used in clinical practice for fetal weight estimation, MRI may be more accurate than two-dimensional ultrasound imaging in fetal weight estimation. Formulas were used for fetal weight estimation based on fetal body volume calculated by MRI [4]. ADC (apparent diffusion coefficient) values of the placenta and fetal organs were studied to detect IUGR (intrauterine growth restriction) fetuses. There was a significant difference in ADC of the placenta, fetal brain, lung, and kidney $(P=0.001,0.001$, 0.04 , and 0.04 , respectively) between IUGR fetuses and the controls [5].

The fetus accumulates most of its body fat during the third trimester. Fetal soft tissue thickness estimation can be useful for better ultrasonography fetal weight 
assessment. These measurements can be done in various parts of the fetus' body. For example, subcutaneous tissue thickness can be measured in the abdomen, thigh, upper arm, or the subscapular area [6].

The purpose of this study was to evaluate the relationship between ultrasonographically assessed FASTT and birth weight.

\section{Methods}

This was a prospective observational study conducted from December 2017 to November 2018 after the approval of the protocol from the Faculty of Medicine ethical committee for human research; fully informed written consent was taken from each patient after explanation of the procedures and the importance of the study. The confidentiality of the patient's data was guaranteed, and the patients had the right to refuse participation in this study without giving any reason.

The study enrolled 100 pregnant females after fulfillment of the inclusion criteria. Inclusion criteria were as follows: singleton pregnancy and gestational age between 37 and 42 weeks. Exclusion criteria were as follows: pregnant women who declined to participate, pregnant females who delivered after more than 1 week from the last fetal biometry, and fetal congenital anomalies.

Patients were subjected to detailed medical history that included personal history, obstetric history, medical and surgical history, and history of present pregnancy. This was followed by an antenatal ultrasonographic examination that was performed by using $2-5 \mathrm{MHz}$ wide band convex, curved array transducer of the HD11 XE Ultrasound System (Philips, Bothell, WA, USA) between 37 and 42 weeks of gestation.

Trans-abdominal obstetric ultrasonography was done starting by patient information entry into the ultrasound system; then, the patient lied in a recumbent position close to the side of the table where the ultrasound device was placed to avoid overstretch of the operator arm to achieve accurate measurements. The patient was asked to adequately expose the abdomen. Lubrication of the abdomen was done with the application of the probe on the patient's abdomen and manipulation in coronal and sagittal planes relative to the structures to be examined [7].

Fetal biometric measures were recorded (BPD, AC, FL, and $\mathrm{HC}$ ); then, fetal weight estimation was done by using Hadlock IV formula (1985) that incorporates fetal biometric measures into the following equation $[8,9]$ :

$\log 10 \mathrm{EBW}=0.3596+(0.00061 \times \mathrm{BPDXAC})+$ $(0.0424 \times \mathrm{AC})+(0.174 \times \mathrm{FL})+(0.0064 \times \mathrm{HC})-$ $(0.00386 \times \mathrm{AC})$

This was followed by FASTT measurement (Figs. 1, 2, 3 and 4 ) and recording. FASTT was measured in millimeters at anterior third of the abdomen at the same level of abdominal circumference by placing the cursor at outer and inner edges of the echogenic subcutaneous fat line.

Follow-up of the patient after delivery was done for the recording of the post-natal fetal weight using a digital scale in supine position after calibration of the scales.

The collected data for statistical analysis included the following: case number, maternal age, gestational age by patient's history, gestational age by US, fetal biometric measures (HC, BPD, AC, and FL), estimated fetal weight (EFW) by Hadlock formula, fetal abdominal subcutaneous tissue thickness obtained by ultrasound, mode of delivery whether NVD (normal vaginal delivery) or CS (cesarean section), fetal gender, and fetal weight at birth.

\section{Statistical analysis}

Data were collected, tabulated, and statistically analyzed using a personal computer with Statistical Package of

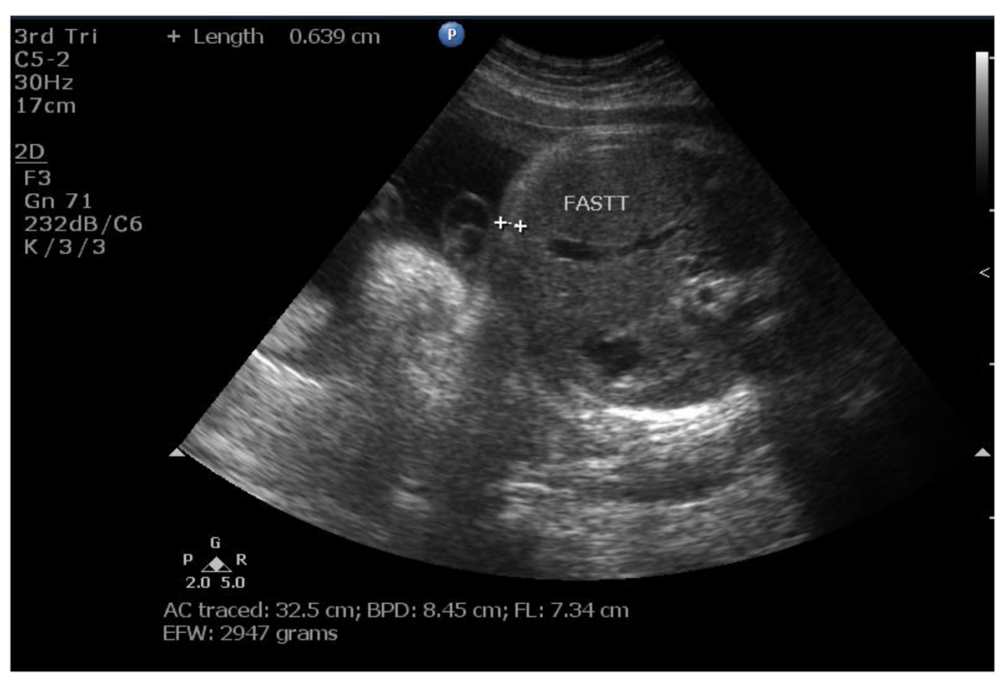

Fig. 1 FASTT measurement at EFW $2947 \mathrm{~g}$ 


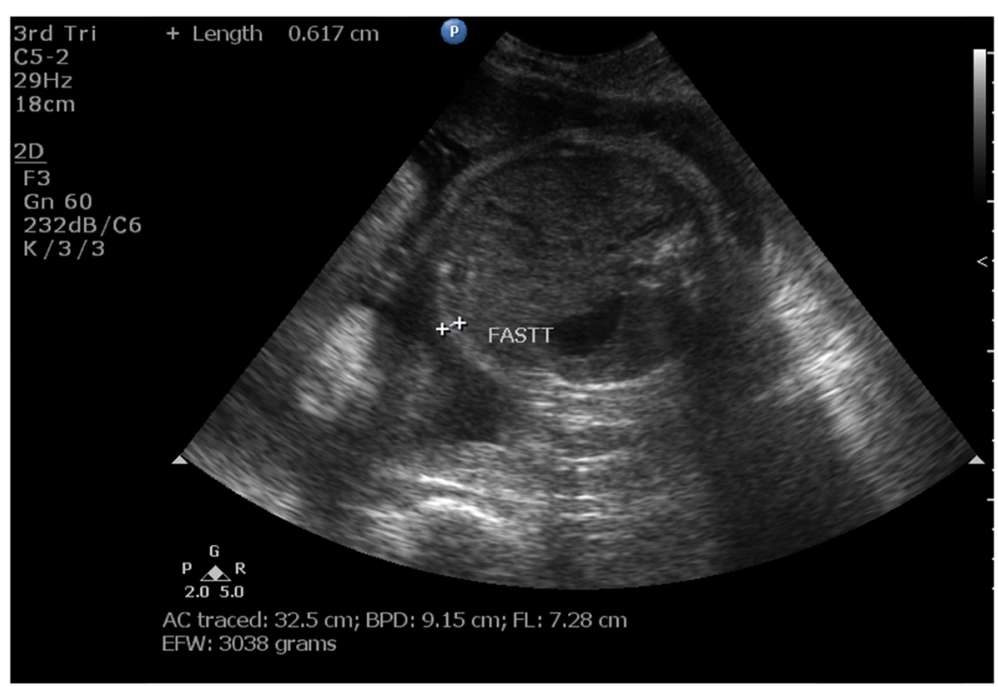

Fig. 2 FASTT measurement at EFW $3038 \mathrm{~g}$

Social Science (SPSS) version 20 [SPSS Inc., Chicago, IL, USA], where two types of statistics were done: descriptive statistics, e.g., number (No.), percentage (\%), mean $(\bar{X})$, and standard deviation (SD), and analytic statistics which included Fisher exact test, one-way ANOVA test, post hoc test, Pearson correlation, Spearman correlation, and ROC curve.

$P$ value at 0.05 was used to determine significance. $P$ value $\geq 0.05$ to be statistically insignificant. P-value $\leq 0.05$ to be statistically significant. P-value $\leq 0.001$ to be highly statistically significant.

\section{Results}

This study included 100 pregnant women. Fourteen percent of the pregnant females were primigravida while
$86 \%$ were multigravida. Gestational age ranged from 37 to 41.6 weeks. No statistical correlation between FASTT and any of the maternal age, gravidity, and parity was found. However, high statistical significant difference was noted between the FASTT and gestational age calculated by date. Fetal biometric measures were estimated as well as FASTT and EFW. FASTT ranged from 3.6 to $13 \mathrm{~mm}$ and EFW ranged from 2275 to $4470 \mathrm{~g}$.

Included subjects in this study were classified into three categories based on the fetal birth weight. FASTT ranged from 3.6 to $4.1 \mathrm{~mm}$ for the SGA category, from 4.2 to $8.7 \mathrm{~mm}$ for the AGA (appropriate for gestational age) category, and from 9 to $13 \mathrm{~mm}$ in LGA category, while EFW of the included subjects ranged from 2275 to $2402 \mathrm{~g}$ in SGA category, from 2569 to $3925 \mathrm{~g}$ for the

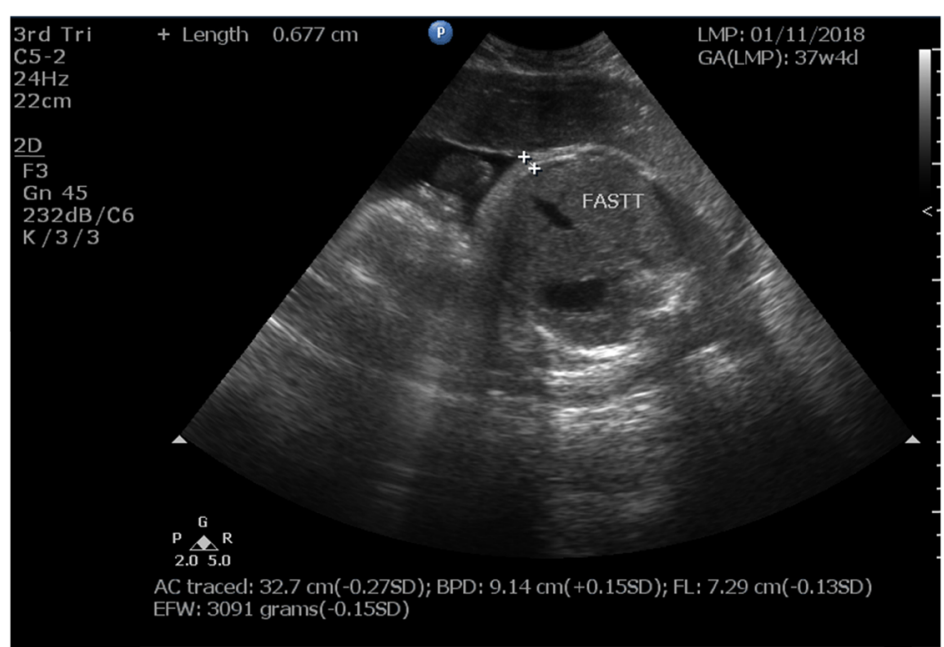

Fig. 3 FASTT measurement at EFW $3091 \mathrm{~g}$ 


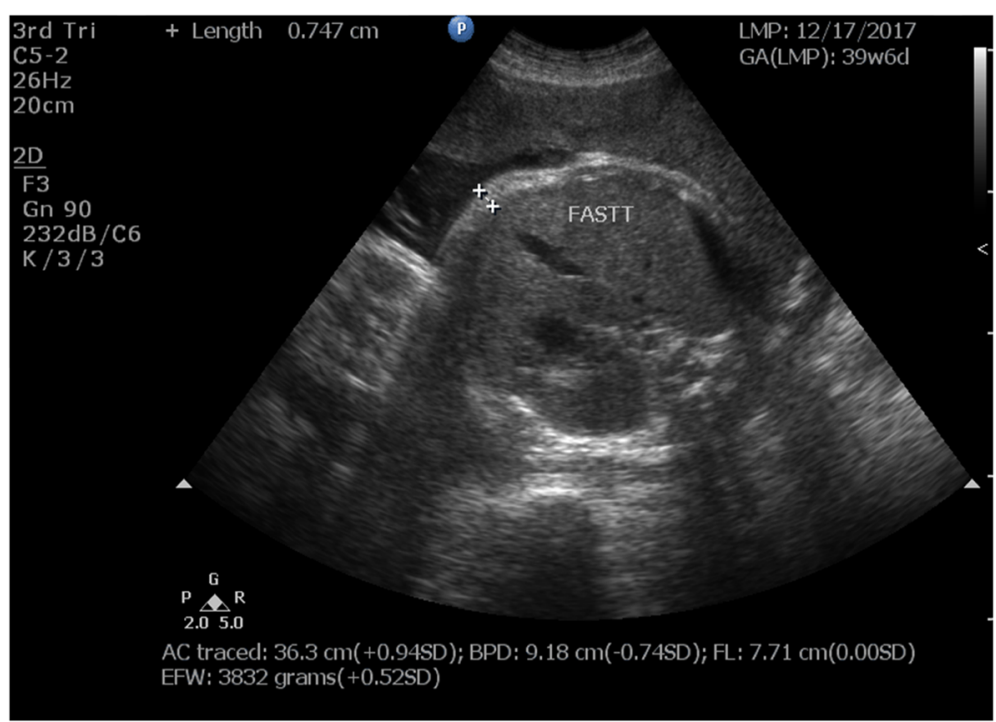

Fig. 4 FASTT measurement at EFW $3832 \mathrm{~g}$

AGA category, and from 4090 to $4470 \mathrm{~g}$ in the LGA category. FASTT showed a high statistically significant correlation with EFW by Hadlock formula and BW (Table 1). Also, a high statistically significant difference between each of the birth weight categories regarding the value of EFW by Hadlock formula as well as by FASTT was found. Both EFW and FASTT showed higher values in LGA category than AGA and SGA categories and also showed higher values in AGA category than SGA category (Table 2).

Comparing sensitivity, specificity, NPV, and PPV for FASTT in LGA and SGA was done. Higher sensitivity of FASTT in LGA than SGA was noted. The best cutoff value of FASTT for LGA was $9.2 \mathrm{~mm}$ and that of SGA was $4.5 \mathrm{~mm}$ (Table 3). Cutoff values were determined by SPSS statistical analysis of ROC curves that represented the sensitivity and specificity of FASTT in LGA and SGA groups (Figs. 5 and 6).

Highly significant statistical correlation was found between FASTT and AC. However, AC showed better accuracy than FASTT in prediction of LGA fetuses (Table 4).

No statistical correlation between fetal gender and FASTT denoting that fat deposition in the fetus is not related to the fetal gender $(r=0.15, p$ value $=0.11(\mathrm{NS})$, Spearman correlation).

Table 1 Correlation between FASTT and EFW as well as BW

\begin{tabular}{lll}
\hline & FASTT & \\
\cline { 2 - 3 } & $r$ & $P$ value \\
\hline EFW & 0.95 & $0.00(\mathrm{HS})$ \\
BW & 0.94 & $0.00(\mathrm{HS})$ \\
\hline$r$ Pearson correlation & &
\end{tabular}

The number of cases with FASTT less than $9.2 \mathrm{~mm}$ was 88 cases. Fifty-two of them had CS while 36 cases had NVD. The number of cases with FASTT more than $9.2 \mathrm{~mm}$ was 12 cases, 11 of them had CS while 1 case had NVD. Despite 91.6\% of pregnant women who had fetuses with FASTT more than $9.2 \mathrm{~mm}$ delivered by $\mathrm{CS}$, no statistical significant difference between FASTT and mode of delivery was found ( $r=0.09, p$ value $=0.23(\mathrm{NS})$, Spearman correlation).

\section{Discussion}

Both macrosomic and growth-retarded fetuses are at an increased risk of perinatal morbidity and mortality [10]. An accurate estimation of fetal weight helps obstetricians in making decision on the route of delivery [11]. Incorporation of fetal soft tissue parameters improves the accuracy of fetal weight estimation [12]. The aim of this study was to assess the accuracy of fetal abdominal subcutaneous tissue thickness as an indicator of fetal birth weight.

The current study concluded that FASTT showed a high statistically significant correlation with EFW by Hadlock formula and BW (birth weight); also, a high statistically significant difference between each of the birth weight categories regarding the value of EFW by Hadlock formula as well as by FASTT was noted. Both EFW and FASTT showed higher values in LGA category than AGA and SGA categories and also showed higher values in AGA category than SGA category

Bhat et al. [10] also agreed with our results; they plotted birth weight against FASTT (scatter plot graph), and it showed a positive significant correlation between FASTT and birth weight obtained by Pearson's 
Table 2 Birth weight groups and sonographic fetal weight of studied pregnant women

\begin{tabular}{|c|c|c|c|c|c|}
\hline Variables & $\begin{array}{l}\text { Birth weight < } 2500 \mathrm{~g} \\
(\mathrm{SGA})(n=8)\end{array}$ & $\begin{array}{l}\text { Birth weight } 2500-4000 \mathrm{~g} \\
(\text { AGA) }(n=80)\end{array}$ & $\begin{array}{l}\text { Birth weight }>4000 \mathrm{~g} \\
(\mathrm{LGA})(n=12)\end{array}$ & Test of sig. & $P$ value \\
\hline \multicolumn{6}{|l|}{ FASTT (mm) } \\
\hline Mean \pm SD & $3.90 \pm 0.16$ & $6.37 \pm 1.23$ & $10.9 \pm 1.22$ & $F=101$ & $0.00 \mathrm{HS}$ \\
\hline Range & $3.6-4.1$ & $4.2-8.7$ & $9-13$ & & \\
\hline Median & 3.95 & 6.40 & 10.9 & & \\
\hline Post hoc & \multicolumn{5}{|c|}{$\mathrm{P} 1=0.00, \mathrm{P} 2=0.00, \mathrm{P} 3=0.00$} \\
\hline \multicolumn{6}{|l|}{ EFW } \\
\hline Mean \pm SD & $2346.1 \pm 51.2$ & $3187.9 \pm 412.3$ & $4266.4 \pm 116.3$ & $F=68.6$ & $0.00 \mathrm{HS}$ \\
\hline Range & $2275-2402$ & $2569-3925$ & $4090-4470$ & & \\
\hline Median & 2352.5 & 3187 & 4261 & & \\
\hline Post hoc & \multicolumn{5}{|c|}{$P 4=0.00, P 5=0.00, P 6=0.00$} \\
\hline
\end{tabular}

$F$ one way ANOVA test, NS non-significant, $S$ significant, $H S$ highly significant

$\mathrm{P} 1$, birth weight $<2500 \mathrm{~g}$ versus birth weight $(2500-4000 \mathrm{~g})$ in FASTT

$\mathrm{P} 2$, birth weight $<2500 \mathrm{~g}$ versus birth weight $>4000 \mathrm{~g}$ in FASTT

P3, birth weight (2500-4000 g) versus birth weight $>4000 \mathrm{~g}$ in FASTT

P4, birth weight $<2500 \mathrm{~g}$ versus birth weight $(2500-4000 \mathrm{~g})$ in EFW

$\mathrm{P} 5$, birth weight $<2500 \mathrm{~g}$ versus birth weight $>4000 \mathrm{~g}$ in EFW

P6, birth weight (2500-4000 g) versus birth weight $>4000 \mathrm{~g}$ in EFW

correlation coefficient $(r=0.418)$. Similarly, Grace et al. [13] demonstrated that FASTT may be useful in the assessment of fetal nutritional risk as they showed a significant correlation between subcutaneous tissue thickness, estimated fetal weight, and actual BW.

Regarding the statistically significant difference of FASTT in different birth weight categories, Odthon et al. [14] showed similar results; they studied the correlation between FASTT and birth weight. The mean FASTT differed significantly between normal and macrosomic fetuses $(6.6 \mathrm{~mm}$ versus $12 \mathrm{~mm}$, respectively; $p<0.001$ ).

Singh et al. [15] agreed to our results; the birth weight was divided according to the percentile in three groups according to which results were statistically significant $(p<0.001)$. Average subcutaneous tissue thickness in babies having a birth weight between 10th and 90th percentile was $5.4 \mathrm{~mm}$. Below 10th percentile was $4.4 \mathrm{~mm}$, and above 90th percentile was $>5.9 \mathrm{~mm}$.

Additionally, the present study results were in accordance with the results recorded by Bhat et al. [10], who found that the difference in mean FASTT between SGA and AGA babies was statistically significant ( $p$ value 0.032). Similarly, the difference in mean FASTT between LGA and AGA babies was also statistically significant ( $p$ value 0.000$)$.
Regarding the demographic data of the included subjects, the current study showed no correlation between FASTT and any of the maternal age, gravidity, and parity; however, a statistically significant correlation was noted between the FASTT and gestational age calculated by date $(r=0.79, P$ value $=0.00)$. Results of Chen et al. [16] and Farah et al. [17] are in agreement with the current study; both found that FASTT measurements increase as gestation advances.

FASTT demonstrated higher sensitivity in LGA (90.9\%) than SGA (86.9\%) denoting that FASTT is a better indicator of LGA than SGA. The best cutoff value of FASTT for LGA was $9.2 \mathrm{~mm}$ and that of SGA was 4.5 $\mathrm{mm}$. Cutoff points of FASTT for LGA and SGA varied in different studies. Close to this result was Mack et al. [12] who found that the best cutoff value for FASTT in detecting macrosomia was $\geq 10.0 \mathrm{~mm}$ with high sensitivity $(81.0 \%)$ and specificity $(86.8 \%)$.

Despite that, Bhat et al. [10] also showed that FASTT was sensitive to predict large for gestational age (LGA) and not sensitive for SGA; a quite different cutoff value of FASTT for large babies was obtained $(6.25 \mathrm{~mm})$. Sensitivity for FASTT $>6.25 \mathrm{~mm}$ for large for gestational age babies was $79 \%$ and specificity is $70 \%$. They also stated that FASTT measurement for the prediction of small babies with birth

Table 3 Sensitivity and specificity of FASTT as a predictor of birth weight $>4000 \mathrm{~g}$ and birth weight $<2500 \mathrm{~g}$

\begin{tabular}{|c|c|c|c|c|c|c|c|}
\hline & $A \cup C$ & $P$ value & Cutoff point (mm) & Sensitivity (\%) & Specificity (\%) & NPV (\%) & PPV (\%) \\
\hline Birth weight $>4000 \mathrm{~g}(\mathrm{LGA})$ & 0.92 & 0.001 & $\geq 9.2$ & 90.9 & 88.9 & 87 & 82 \\
\hline Birth weight $<2500 \mathrm{~g}(\mathrm{SGA})$ & 0.90 & 0.002 & $\leq 4.5$ & 86.9 & 92 & 84 & 87 \\
\hline
\end{tabular}




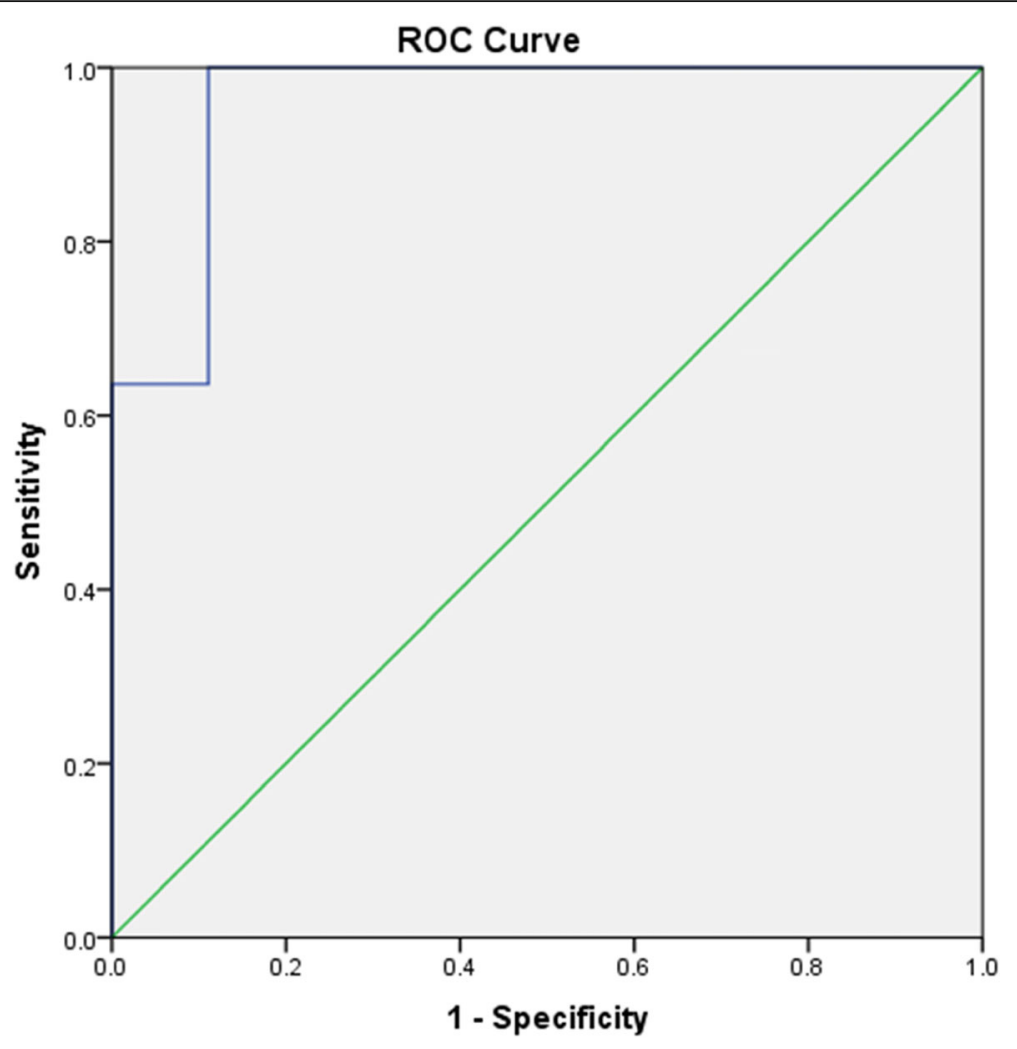

Fig. 5 ROC curve for FASTT as a predictor of birth weight $>4000 \mathrm{~g}(\mathrm{LGA})$

weight $<2500 \mathrm{~g}$ was not sensitive. Therefore, a cutoff value of FASTT for small for gestational age babies could not be obtained.

Regarding SGA, the results of the current study were comparable to the results obtained by Kongsing et al. [18], who found that the best cutoff value of the subcutaneous fat thickness for prediction of IUGR was 4.5 $\mathrm{mm}$, giving the sensitivity, specificity, positive predictive value, and negative predictive value of $76.0 \%, 75.3 \%$, $47.5 \%$, and $91.4 \%$, respectively.

Close to our results was Prasertcharoensuk et al. [19] who found that fetuses with FASTT $\leq 4 \mathrm{~mm}$ were more likely to have low birth weight with a sensitivity of $90.0 \%$ (95\% CI $=86.8-93.3)$ and a specificity of $53.5 \%$.

As FASTT showed high statistical correlation with AC among the other fetal biometric parameters, comparing $A C$ versus FASTT in cases of LGA was done; this is in conformity with Odthon et al. [14] who evaluated the value of the sonographic measurement of fetal AC and FASTT for predicting fetal macrosomia. Compatible results were obtained. Our study showed higher values for AC than FASTT (accuracy of 96\% for AC against 92\% for FASTT) as well as Odthon et al. [14] study (accuracy of $93.4 \%$ for AC against $86.4 \%$ for FASTT) denoting that $\mathrm{AC}$ is still a better parameter for detection of LGA.
This study showed no statistical correlation between fetal gender and FASTT denoting that fat deposition in the fetus is undependable from the fetal gender. Similarly, Farah et al. [17] demonstrated that the FASTT increases at the same rate for both male and female fetuses and at any given week.

In the current study, correlation between FASTT and mode of delivery was done; despite $91.6 \%$ of pregnant women who had fetuses with FASTT more than $9.2 \mathrm{~mm}$ delivered by CS, no statistical significant difference between FASTT and mode of delivery could be detected.

In accordance with the result of this study, Grace et al. [13] agreed that no direct relationship between FASTT and mode of delivery could be found. Also, Assimakopoulos et al. [20] found that fetuses with low FASTT were more likely to be delivered through normal vaginal delivery $(7.8 \pm 0.1 \mathrm{~mm})$, while higher FASTT was correlated with instrumental vaginal delivery $(7.9 \pm 0.2 \mathrm{~mm})$ and cesarean section $(8.6 \pm 0.3 \mathrm{~mm})$ (ANOVA, $P=$ 0.034). With increasing FASTT, the likelihood of instrumental vaginal and cesarean delivery increased but with no direct significant statistical correlation.

As FASTT showed a positive correlation with a wide range of fetal weights, it can be incorporated into 


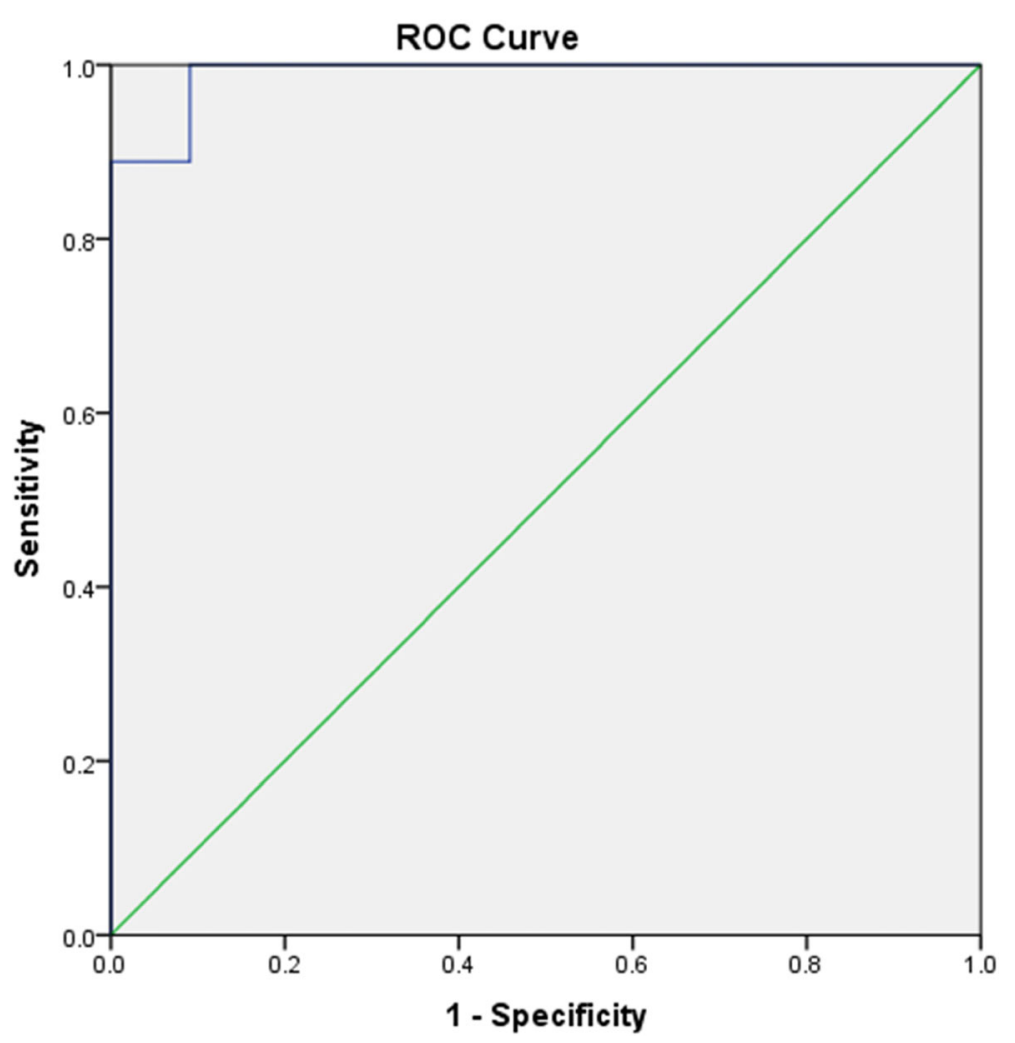

Fig. 6 ROC curve for FASTT as a predictor of birth weight $>2500 \mathrm{~g}$ (SGA)

ultrasonographic weight estimation formulas to achieve better accuracy; it can be used as an alternative to $\mathrm{AC}$ in modified formulas when accurate AC measurement cannot be obtained. The cutoff values may serve as a fast predictor for macrosomia and IUGR for pregnant women in labor. The study was limited by the difficulty of measuring FASTT in obese patients, in cases with anteriorly situated placenta, cases of twins, and when the fetal presentation was occipito-anterior.

\section{Conclusion}

FASTT is a good indicator of birth weight; it is a better parameter for LGA than SGA. It showed a high statistically significant correlation with AC, yet it is less accurate than $\mathrm{AC}$ as an indicator of fetal macrosomia. FASTT is not affected by fetal gender and has no direct relation to the mode of delivery.

Table 4 The diagnostic value of AC and FASTT as predictor for fetal macrosomia

\begin{tabular}{llllll}
\hline & Accuracy (\%) & Sensitivity (\%) & Specificity (\%) & NPV (\%) & PPV (\%) \\
\hline AC & 96 & 94.8 & 90.7 & 90 & 85 \\
FASTT & 92 & 90.9 & 88.9 & 87 & 82 \\
\hline
\end{tabular}

\section{Abbreviations}

AC: Abdominal circumference; ADC: Apparent diffusion coefficient: AGA: Appropriate for gestational age; BPD: Biparietal diameter; BW: Birth weight; CS: Cesarean section; EFW: Estimated fetal weight; FASTT: Fetal abdominal subcutaneous tissue thickness; FL: Femur length; HC: Head circumference; LGA: Large for gestational age; MRI: Magnetic resonance imaging; NVD: Normal vaginal delivery; SGA: Small for gestational age

\section{Acknowledgements}

Not applicable

\section{Authors' contributions}

EK conceived the design of the work, collected the data, performed the analysis, and wrote the manuscript with input from all authors. SH presented the idea of the study, aided in interpreting the results, and critically revised and co-wrote the manuscript. HE supervised and encouraged the project, approved the presented idea, supervised the findings of the study, and aided in its interpretation, and contributed to the final version of the manuscript. All authors have read and approved the manuscript.

\section{Funding}

There is no funding.

\section{Availability of data and materials}

Data will be available upon request via contacting the corresponding author.

\section{Ethics approval and consent to participate}

All study procedures were conducted in accordance with the Declaration of Helsinki and were approved by the ethical committee and Menoufia Faculty of Medicine council, reference number 37/13/8/2017. Fully informed written consent was taken from each patient after explanation of the procedures and the importance of the study, and the confidentiality of the patient's data was guaranteed. 


\section{Consent for publication}

All patients included in this research gave written informed consent to publish the data contained within this study.

\section{Competing interests}

The authors declare that they have no competing interests.

Received: 24 September 2019 Accepted: 27 November 2019

Published online: 12 December 2019

\section{References}

1. Bergan-Roller HE, Ickstadt AT, Kittilson JD (2017) Insulin and insulin-like growth factor-1 modulate the lipolytic action of growth hormone by altering signal pathway linkages. Gen Comp Endocrinol 248:40-48

2. Monier I, Ancel PY, Ego A (2017) Fetal and neonatal outcomes of preterm infants born before 32 weeks of gestation according to antenatal vs postnatal assessments of restricted growth. Am J Obstet Gynecol 216(5):516. e1-516.e10

3. Wu M, Shao G, Zhang F (2015) Estimation of fetal weight by ultrasonic examination. Int J Clin Exp Med 8(1):540

4. Kadji C, Cannie M, Resta S, Guez D, Khalil FA, Jani JC (2018) Magnetic resonance imaging for prenatal estimation of birth weight in pregnancy: review of available data, techniques, and future perspectives. Am J Obstet Gynecol 220(5):428-439

5. Razek A, Thabet M, Salam E (2019) Apparent diffusion coefficient of the placenta and fetal organs in intrauterine growth restriction. J Comput Assist Tomogr 43(3):507-512

6. Moore GS, Allshouse AA, Fisher BM (2016) Can fetal limb soft tissue measurements in the third trimester predict neonatal adiposity? J Ultrasound Med 35(9):1915-1924

7. Alfred A (2014) Technical aspects of the ultrasound examination. In: Rabih C Phillipe J, Dario P (eds) Ultrasound in Obstetrics \& Gynecology: A Practical Approach, 1st edn

8. Hadlock FP, Harrist RB, Sharman R (1985) Estimation of fetal weight with the use of head, body and femur measurements a prospective study. Am J Obstet Gynecol 151(3):333-337

9. Norton ME, Scout LM, Feldstein VA (2016) Fetal biometry and growth. In: Benson CB, Doubilet PM (eds) Callen's Ultrasonography in Obstetrics and Gynecology, 6th edn. Elsevier, Philadelphia

10. Bhat RG, Nathan A, Amar R (2014) Correlation of fetal abdominal subcutaneous tissue thickness by ultrasound to predict birth weight. J Clin Diagn Res 8(4):OC09

11. Maroufizadeh S, Almasi-Hashiani A, Esmaeilzadeh A (2017) Prevalence of macrosomia in Iran: a systematic review and meta-analysis. Int J Pediatr 5(9): 5617-5629

12. Mack L, Kim S, Lee S (2017) Automated fractional limb volume measurements improve the precision of birth weight predictions in late third-trimester fetuses. J Ultrasound Med 36(8):1649-1655

13. Grace DL, Josefina PK (2012) Fetal abdominal subcutaneous tissue thickness (FASTT): correlation with other biometric measures and neonatal outcomes in a sample population of philipino fetuses. Philipp J Obstet Gynecol 36(3): 117-148

14. Odthon T, Pitukkijronnakorn S, Chittacharoen A (2015) Sonographic measurement fetal abdominal circumference and fetal abdominal subcutaneous tissue thickness for predicting fetal macrosomia. J Obstet Gynaecol 5:216-222

15. Singh A, Chander R, Kumari S (2014) Estimation of fetal weight and its correlation with actual birth weight by sonographic measurement of fetal abdominal subcutaneous tissue thickness. J Evol Med Dent Sci 3(37):96109621

16. Chen L, Wu JJ, Cao L et al (2014) Measurement of fetal abdominal and subscapular subcutaneous tissue thickness during pregnancy to predict macrosomia: a pilot study. PloS one 9(3):e93077

17. Farah N, Stuart B, Harrold E (2010) Are there sex differences in Feta Abdominal Subcutaneous Tissue (FAST) measurements? Eur J Obstet Gynecol 148(2):118-120

18. Kongsing K, Wanapirak C, Tongsong T (2003) Accuracy of ultrasonic fetal abdominal subcutanous fat thickness measurement in predicting intrauterine growth restriction (IUGR). Thai J Obstet Gynaecol 43(1):79-83
19. Prasertcharoensuk W, Bunlengsanoh P (2003) Fetal abdominal subcutaneous fat thickness as a predictor of low birth weight in term pregnancy. Srinagarind Med J 18(2):90-95

20. Assimakopoulos E, Zafrakas M, Garmiris P (2007) Fetal abdominal subcutaneous tissue thickness measured by ultrasound at term is associated with birth weight and mode of delivery. Clin Exp Obstet Gynecol 34(3):171-174

\section{Publisher's Note}

Springer Nature remains neutral with regard to jurisdictional claims in published maps and institutional affiliations.

\section{Submit your manuscript to a SpringerOpen ${ }^{\circ}$ journal and benefit from:}

- Convenient online submission

- Rigorous peer review

- Open access: articles freely available online

- High visibility within the field

- Retaining the copyright to your article

Submit your next manuscript at $\boldsymbol{\nabla}$ springeropen.com 